\title{
Does the Internet Use Improve People's Sense of Social Equity?
}

An empirical research based on the Chinese General Social Survey, 2013

WEI ZHANG

School of Social Development, East China University of Political Science and Law, Shanghai 201620, China

Email: zh-wei@outlook.com

\begin{abstract}
The Internet has reconstructed our understanding of the world. As one of the most important indicators to measure the society, people's sense of social equity is also affected by their use of Internet. In consideration of the incongruity between the dramatic growth of China's Internet and the online mass incidents happening more often, this paper supposes that the Internet use has a negative effect on people's sense of social equity in China. Data from the Chinese General Social Survey (2013) confirms this assumption, and the reason behind that can be summarized as follows: (1) the Internet helps people recognize the social realities which may be covered by traditional media sometimes; (2) the non-institutionalized participation in the network space let people know that there are plenty of scope for improvement. Furthermore, this paper analyses the moderating effect of the education and residence on the relationship between Internet use and people's sense of social equity. And the significant moderating effect suggests that the relationship is relatively flat for higher educated and urban people, but steep for less educated and rural people.
\end{abstract}

Keywords: Internet use, sense of social equity, non-institutionalized participation, digital divide

\section{INTRODUCTION}

Like a coin has two sides, there is a positive aspect and a negative aspect to China's gradual reform. The positive aspect manifests in the rapid economic development of the country and the significant improvement of people's living standard; whereas the negative aspect is mainly reflected in the increased social inequality involving the traditional wealth and opportunity, as well as the recent emergence of information possession and expression. Since the birth of the Internet, countless people believe that it will produce a more equal society because access to the Internet means access to information and communication networks, which will help improve education, health, and career outcomes of the whole society. Taking China as an example, the number of Internet users reaches 0.731 billion by the end of 2016, according to the data from the 39th China Statistical Report on Internet Development. The reasons why internet users increase so fast can be summed up into two aspects. One is that the Internet does not only connect people to their friends and family, but also links people to job opportunities, 
critical services, and troves of information (Blasio 2015). The other is that the price of Internet terminals and access services has fallen to the level that most people can afford. However, it remains a question whether the prevailing use of the Internet could really improve people's sense of social equity as most people think. It seems that the Internet brings forth a means of communication that is for the public, by the public (Curran, Gurevitch 2005). But in fact, the Internet exposes a truer appearance of the world to people so that they may deem their living society is not as good as they have ever known. According to the theory of pseudo-environment, the real environment is altogether too big, too complex and too fleeting for direct acquaintance, so that people cannot get pictures about the world outside directly but have to resort the mass media indirectly. However, the mass media is not a mirror of reality; what it shows is often arranged to portray a certain, subjective interpretation of events (Lippmann 1922). As a new communication media, the Internet shows realistic images about the society including the potential conflicts and discords which are generally limited reporting on traditional media. So, the Internet use may exacerbate people's sense of social inequity.

Apparently, the mass media plays a very important role in people's social life, as most of the information people received comes from media, and the picture of the world inside people's mind is also practically drawn by the media. At present, the Internet is the most popular media, and social equity is one of the issues that concern people. In order to reveal the relationship between the Internet use and people's sense of social equity, this paper adopts statistical models for ranked data by using the empirical data of the Chinese General Social Survey, 2013 (CGSS2013). Moreover, this paper illustrates how Internet use affects people's sense of social equity by adding the interaction terms to the statistical model.

\section{LITERATURE REVIEW}

\section{The social consequence of Internet}

Castells (2010) once noted that the Internet had posted the fastest rate of penetration of any communication medium in history. The Internet creates new ways for people to communicate, congregate, and share information of a social nature (Alrawabdeh 2014). Besides, it has a role to play in every corner of human life. When it comes to the social impact of the Internet, there are at least three aspects according to the existing research.

First, the Internet has changed the structure of social power (Li 2013). In the Internet era, the information power, which is different from the traditional social power, lies in the codes of information and in the images of representation (Castells 2009), and is becoming the most interactive and influential power in the world. This Internet-use-based power is given by the online communicative behaviours which include posting opinions, conveying messages, and commenting current events. In the cyberspace, even people at the bottom of society could be free to verbalize their opinions and attitude on certain problems. Thus, the decentration has gradually become one of the most important characters of social power, which means the structure of traditional social power has been deconstructed in a way.

Second, the Internet has expanded the scope of social interaction. The Internet communication expands people's horizons and broadens people's understandings by offering a multitude of sites for debate among people with varied opinions. Holt (2004) states that the ability of the Internet to unite those of disparate backgrounds has a great potential for fostering debate and discussion of issues in the civic arena. And the online political discussion serves to expose 
participants to non-likeminded partners (Brundidge 2006). Indeed, the Internet creates a public-sphere-liked field where people could discuss public affairs with relatively more freedom.

Third, the Internet has diversified the people's interest expressing channel. Politically speaking, the citizens of a country comprise a few elite and large numbers of civilians. And by using the Internet, the opinion expressing channel of both elite and civilians is becoming smoother than ever. On the one hand, the elite are more likely to become Internet opinion leaders as the resources they have in reality can be easily transformed into advantages in the cyberspace; on the other hand, the Internet can better meet the interests of civilians. What is more, the Internet builds a bridge for the communication between the elite and the civilians. And this phenomenon is more apparent in authoritarian regimes or developing democracies. As in such countries, the use of Internet has undoubtedly enabled otherwise repressed voices to be heard (Curran, Gurevitch 2005).

\section{The impact of Internet use on the sense of social equality}

How people understand themselves and the outside world is heavily dependent on the media environment in the current information society. Most people are living in the pseudo-environment molded by mass media rather than in the real-environment. For instance, the more time people spend 'living' in the television world, the more likely they are to believe the social reality aligns with the reality portrayed on television (Riddle 2009). Comparing with the traditional mass media, what are the characteristics of the environment molded by the Internet? It is much easier to get information from the public and get information out to them when accessing the Internet. Nevertheless, the Internet is not that perfect. As the rules on censorship of the Internet are relatively looser than those of the traditional media, information on the Internet is much more messy and extreme. In some developing democracies, as it is difficult to express one's interest in a normal legal way, people, especially those in lower classes, usually view the Internet as the most effective channel for counter-expression (Curran et al. 2014). But for ordinary users, the information they get from the Internet does not represent the true appearance of the society. The reason can be summarized in two aspects: (1) The scandals and negative issues spread fast in the cyberspace (Zuckerman 2014). In order to catch the eyes of Internet users, the websites prefer to post and forward the news about scandals and negative issues. Living in the environment filled with such information, Internet users are more likely to have a horrible impression on the reality. (2) As a result of information explosion, people rarely pore over the information but usually follow the herd nowadays, as accessing the information does not mean having ideas. Without rational thinking, one's understanding of the society is the same as that delineated by his most commonly used media.

As one of the most important indicators used to measure the society, social equity is usually defined as the fair and equitable distribution of resources and opportunities, advocating for the right of the least privileged members (Schneider et al. 2012). Social equity measures a society macroscopically, but from the perspective of an individual, it is a sense of the society on the basis of one's received social information. Because the Internet has become the leading source of news and information (Barthel et al. 2015), it will have a profound impact on people's sense of social equity (Christians 2016). Some scholars (Rheingold 2002; Gillmor 2004; Beckett 2008; Shirky 2008; Papacharissi 2009) argue that the impact is positive as the Internet informs people about different issues. If something unfair happens somewhere in the country, people would share links, videos, and as much information as they can with their followers. They can even create an online community, in which all the members discuss the issue and try 
to solve it. Another argument is that the Internet use has a negative influence on people's sense of social equity because people can easily fall into the 'information trap' - the websites usually have the preferences to publish the eye-catching news which sometimes arouse people's emotion of resentment. As Couldry (2003) has suggested, once the media presents itself as the center of society and people organize their lives and orient their daily rituals and practice towards it, they run the risk of falling prey to 'the myth of the mediated center'.

\section{Research hypothesis}

After reviewing the literature on the social consequence of Internet and the impact of Internet use on the sense of social equality, and considering the particularity of Chinese society, where the Internet is becoming an important and effective channel for counter-expression, this study derives the following empirical implication:

Hypothesis 1. The sense of social equity is negatively correlated with people's information getting frequency via the Internet.

People's sense of social equity is, on the one hand, related to the fairness of resource allocation and the social governance status; on the other hand, depends on whether people can accurately evaluate the society. The latter involves people's cognitive abilities which vary with people's education and the place where they live. Relatively, the horizons of less educated and rural people are usually narrower than higher educated and urban people, so different people usually have different views when facing the same information about the society, especially for the negative information which is spreading fast in the network space. In this light, I take the education and residence as moderating variables and generate the following two hypotheses based on Hypothesis 1:

Hypothesis 2. The impact of the Internet use on people's sense of social equity varies with the education of them.

Hypothesis 3. The impact of the Internet use on people's sense of social equity varies with the residence of them.

\section{RESEARCH DESIGN}

\section{Data}

The data used in this study comes from CGSS2013, an annual representative sample survey of China's urban and rural households. CGSS is administrated by the Department of Sociology of the Renmin University of China and the Survey Research Center of the Hong Kong University of Science and Technology. And the survey uses the multistage hierarchical PPS sampling method to obtain samples: (1) 100 counties/districts extracted from the nationwide, and 5 big cities, Beijing, Shanghai, Tianjin, Guangzhou and Shenzhen, are selected as the primary sampling units; (2) 480 communities/villages are selected by random sampling; (3) 25 households are then randomly selected in each community/village; (4) one person is selected as the subject of investigation in each household by using the Kish table. Finally, 11,438 questionnaires are completed through a face-to-face interview.

\section{Measures}

The study focuses on people's sense of social equity in China which is measured using the question 'In general, how do you feel about the social equity?' in CGSS2013. The responses are set 
as a five-point Likert scale: 'utterly unfair,' 'unfair,' 'neutral', 'fair', and 'totally fair', which are encoded from 1 to 5 .

The key independent variable is the frequency of people using the Internet. In CGSS2013, there are two questions that may serve as the measure: (1) 'In the past year, how often do you use the Internet?' with the responses 'never,' 'rarely', 'occasionally', 'frequently', 'very frequently'; (2) 'In the past year, how often do you use the Internet in your leisure time?' with the responses 'everyday,' 'several times a week', 'several times a month, 'several times a year', and 'never.' Because the interviewees are asked 'which media is your most important source of information?' after they answer the former question, so it is mainly about getting information via the Internet; whereas the latter question is asked with the frequency of seeing films, meeting friends, participating in cultural activities, etc., so it is a comprehensive measure of people's Internet use. The variables formed by these two questions will be used separately in the analysis of this study.

Besides, the statistical model also adds some control variables including gender, age, nationality, education, political status, residence, marital status, the logarithm of personal annual income, and the self-rated social stratum. Means and standard deviations for the variables mentioned above are given in Table 1 .

Table 1. Descriptive statistics of variables $(N=8912)$

\begin{tabular}{c|c|c|c|c}
\hline Variable & Mean & $\begin{array}{c}\text { Std. } \\
\text { Dev }\end{array}$ & Min & Max \\
\hline $\begin{array}{c}\text { Sense of } \\
\text { social equity }\end{array}$ & 3.010 & 1.047 & 1 & 5 \\
\hline $\begin{array}{c}\text { Internet use } \\
(1)\end{array}$ & 2.183 & 1.547 & 1 & 5 \\
\hline $\begin{array}{c}\text { Internet use } \\
(2)\end{array}$ & 2.278 & 1.678 & 1 & 5 \\
\hline Gender & 0.547 & 0.498 & 0 & 1 \\
\hline Age & 49.33 & 15.71 & 17 & 97 \\
\hline Nationality & 0.915 & 0.279 & 0 & 1 \\
\hline Education & 8.907 & 4.572 & 0 & 19 \\
\hline $\begin{array}{c}\text { Political } \\
\text { status }\end{array}$ & 0.118 & 0.323 & 0 & 1 \\
\hline Residence & 0.467 & 0.499 & 0 & 1 \\
\hline $\begin{array}{c}\text { Marital } \\
\text { status }\end{array}$ & 2.012 & 0.434 & 1 & 3 \\
\hline ln_income & 9.622 & 1.183 & 4.382 & 13.82 \\
\hline $\begin{array}{c}\text { Social } \\
\text { stratum }\end{array}$ & 4.350 & 1.671 & 1 & 10 \\
\hline
\end{tabular}

Note: gender $(0=$ female, $1=$ male $)$, nationality $(0=$ minority, $1=$ Han nationality $)$, political status $(0=$ non-party people, $1=$ party member $)$, residence $(0=$ rural, $1=$ urban $)$, marital status $(1=$ single, $2=$ married, 3 = divorced or widowed), social stratum ( 1 = highest, 10 = lowest $)$.

\section{Method}

As the dependent variable is constructed as an ordinal variable, this study uses the ordered logistic regression to analyse how well the response of a person to the dependent variable can be predicted by the responses to the explanatory variable and control variables. The cumulative probability for the $i^{\text {th }}$ individual up to the response level $j$ can be written as

$$
\operatorname{Pr}\left(y_{i} \leq j \mid x_{i}\right)=\frac{\exp \left(\alpha_{j}+x_{i}^{\prime} \beta\right)}{1+\exp \left(\alpha_{j}+x_{i}^{\prime} \beta\right)},
$$

where the vector $x_{i}$ contains the independent variables including the key explanatory variable and control variables. As this model is linear in the logistic scale, letting $l_{j}\left(x_{i}\right)$ denotes the cumulative logit of $y \leq j$ versus $y>j$, Eq. (1) can be converted to

$$
l_{j}\left(x_{i}\right)=\log \left[\frac{\operatorname{Pr}\left(y_{i} \leq j \mid x_{i}\right)}{\operatorname{Pr}\left(y_{i}>j \mid x_{i}\right)}\right]=\alpha_{j}+x_{i}^{\prime} \beta
$$

In addition, variables used for constructing the interaction terms are mean centered 
for reducing the covariance between the linear and the interaction terms (Xie et al. 2011). And the statistical analysis in this study is performed by the Stata version 13.1 for Windows (Stata Corp, College Station, TX).

\section{RESULTS OF DATA ANALYSIS}

Table 2 explores whether Internet use affects people's sense of social equity by creating nested models. Among the models, model 1 is the benchmark model which only includes the control variables. In model 1, the nationality, education, residence, marital status (married people, compared with single ones), income (in logarithm) show significant and negative effects on people's sense of social equity; whereas the political status and social stratum show a significant and positive effects on people's sense of social equity. Model 2 and model 3 add the key independent variables Internet use (1) and Internet use (2) in the model separately. The parameter estimates in these two models are nearly the same, Internet use (1) and Internet use (2) both have a significant negative effect on the dependent variable after controlling the effect of all the control variables. In other words, with the increase in the frequency of Internet use, people are more likely to think that the society is unfair. Therefore, Hypothesis 1 is confirmed in both cases.

Table 2. Estimation results of people's sense of social equity using the ordered logistic regression

\begin{tabular}{|c|c|c|c|c|c|c|}
\hline Variables & \multicolumn{2}{|c|}{ Model 1} & \multicolumn{2}{|c|}{ Model 2} & \multicolumn{2}{|c|}{ Model 3} \\
\hline Internet use (1) & & & $-0.048^{\star * *}$ & $(0.019)$ & & \\
\hline Internet use (2) & & & & & $-0.048^{* * *}$ & $(0.017)$ \\
\hline Gender & 0.003 & $(0.041)$ & 0.001 & $(0.041)$ & 0.001 & $(0.041)$ \\
\hline Age & -0.001 & $(0.008)$ & -0.008 & $(0.009)$ & -0.009 & $(0.009)$ \\
\hline Age2 & 0.000 & $(0.000)$ & $0.000^{* *}$ & $(0.000)$ & $0.000^{* *}$ & $(0.000)$ \\
\hline Nationality & $-0.219^{* * *}$ & $(0.076)$ & $-0.209^{* * *}$ & $(0.076)$ & $-0.208^{* * *}$ & $(0.076)$ \\
\hline Education & $-0.023^{* * *}$ & $(0.006)$ & $-0.019^{* * *}$ & $(0.006)$ & $-0.019^{* * *}$ & $(0.006)$ \\
\hline Political status & $0.168^{\star \star *}$ & $(0.064)$ & $0.177^{\star * *}$ & $(0.064)$ & $0.176^{* * *}$ & $(0.064)$ \\
\hline Residence & $-0.419^{* * *}$ & $(0.050)$ & $-0.402^{* * *}$ & $(0.050)$ & $-0.400^{* * *}$ & $(0.050)$ \\
\hline \multicolumn{7}{|l|}{ Marital status } \\
\hline Married & $-0.135^{\star}$ & $(0.077)$ & $-0.146^{*}$ & $(0.077)$ & $-0.144^{*}$ & $(0.077)$ \\
\hline Divorced/widowed & -0.037 & $(0.102)$ & -0.042 & $(0.102)$ & -0.040 & $(0.102)$ \\
\hline ln_income & $-0.074^{* * *}$ & $(0.023)$ & $-0.066^{* * *}$ & $(0.023)$ & $-0.065^{\star * *}$ & $(0.023)$ \\
\hline Social stratum & $0.218^{\star \star *}$ & $(0.014)$ & $0.219^{* * *}$ & $(0.014)$ & $0.219^{* * *}$ & $(0.014)$ \\
\hline Constant cut1 & $-2.774^{* * *}$ & $(0.276)$ & $-2.967^{\star * *}$ & $(0.287)$ & $-2.976^{* * *}$ & $(0.286)$ \\
\hline Constant cut 2 & $-0.776^{* * *}$ & $(0.275)$ & $-0.967^{\star * *}$ & $(0.286)$ & $-0.976^{* * *}$ & $(0.284)$ \\
\hline Constant cut 3 & 0.191 & $(0.275)$ & 0.000 & $(0.285)$ & -0.009 & $(0.284)$ \\
\hline Constant cut 4 & $3.351^{\star * *}$ & $(0.283)$ & $3.160^{\star * *}$ & $(0.293)$ & $3.152^{\star * *}$ & $(0.292)$ \\
\hline Observations & \multicolumn{2}{|c|}{8.912} & \multicolumn{2}{|c|}{8.912} & \multicolumn{2}{|c|}{8.912} \\
\hline Wald $\chi 2$ & \multicolumn{2}{|c|}{526.57} & \multicolumn{2}{|c|}{534.38} & \multicolumn{2}{|c|}{534.75} \\
\hline Pseudo R-squared & \multicolumn{2}{|c|}{0.0245} & \multicolumn{2}{|c|}{0.0247} & \multicolumn{2}{|c|}{0.0248} \\
\hline
\end{tabular}

Note: Robust standard errors in parentheses; ${ }^{* * *} p<0.01,{ }^{* *} p<0.05,{ }^{*} p<0.1$. 
After confirming the negative effect of the Internet use on people's sense of social equity, the following question deserves to be studied: Is the relationship between these two variables regulated by some particular variables? As a new type of mass media, whether people can accurately distinguish the information that they get from the Internet will be influenced by their social awareness. Based on this, this study chooses educational level and residence as moderators, then adding the interaction items constructed from the frequency of Internet use to the estimation model, respectively. As the estimation results of model 2 and model 3 in Table 2 are nearly the same, model 4 and model 5 are built on the basis of model 2 as a convenience. And the estimation results are shown in Table 3.

According to the estimation results in Table 3, positive and statistically significant coefficient values for the two interaction terms, Internet use $(1) \times$ education and Internet use (1) $\times$ residence, can be observed, which provides support for Hypothesis 2 and Hypothesis 3 . In other words, it is demonstrated that the influence of Internet use on people's sense of social equity varies with people's education and residence. In order to better understand the moderation of these two variables, marginal effects of the Internet use on people's sense of social equity with moderators are graphically estimated from model 4 and model 5 in the Figure.

Table 3. Estimation results of interaction models

\begin{tabular}{|c|c|c|c|c|}
\hline Variables & \multicolumn{2}{|c|}{ Model 4} & \multicolumn{2}{|c|}{ Model 5} \\
\hline Internet use (1) & $-0.214^{\star * *}$ & $(0.045)$ & $-0.131^{\star * *}$ & $(0.025)$ \\
\hline Gender & 0.015 & $(0.041)$ & 0.002 & $(0.041)$ \\
\hline Age & 0.008 & $(0.009)$ & $0.016^{*}$ & $(0.009)$ \\
\hline Age2 & $0.000^{\star *}$ & $(0.000)$ & $0.000^{* * *}$ & $(0.000)$ \\
\hline Nationality & $0.214^{\star * *}$ & $(0.076)$ & $0.205^{\star * *}$ & $(0.076)$ \\
\hline Education & $0.045^{\star * *}$ & $(0.009)$ & $0.020^{\star * *}$ & $(0.007)$ \\
\hline Political status & $0.158^{\star *}$ & $(0.065)$ & $0.170^{\star * *}$ & $(0.064)$ \\
\hline Residence & $0.415^{\star * *}$ & $(0.051)$ & $0.702^{\star * *}$ & $(0.081)$ \\
\hline \multicolumn{5}{|l|}{ Marital status } \\
\hline Married & 0.120 & $(0.077)$ & $0.147^{\star}$ & $(0.077)$ \\
\hline Divorced/widowed & 0.024 & $(0.102)$ & 0.036 & $(0.102)$ \\
\hline ln_income & $-0.059^{* *}$ & $(0.023)$ & $0.047^{\star *}$ & $(0.023)$ \\
\hline Social stratum & $0.219^{\star * *}$ & $(0.014)$ & $0.218^{\star * *}$ & $(0.014)$ \\
\hline Internet use $(1) \times$ education & $0.014^{\star * *}$ & $(0.003)$ & & \\
\hline Internet use $(1) \times$ residence & & & $0.132^{\star * *}$ & $(0.027)$ \\
\hline Constant cut1 & $3.156^{\star * *}$ & $(0.293)$ & $3.144^{\star * *}$ & $(0.290)$ \\
\hline Constant cut2 & $1.156^{\star * *}$ & $(0.291)$ & $1.143^{\star * *}$ & $(0.288)$ \\
\hline Constant cut3 & 0.187 & $(0.291)$ & 0.173 & $(0.288)$ \\
\hline Constant cut 4 & $2.976^{\star * *}$ & $(0.298)$ & $2.992^{\star * *}$ & $(0.296)$ \\
\hline Observations & \multicolumn{2}{|c|}{8.912} & \multicolumn{2}{|c|}{8.912} \\
\hline Wald $\chi^{2}$ & \multicolumn{2}{|c|}{547.59} & \multicolumn{2}{|c|}{553.50} \\
\hline Pseudo R-squared & \multicolumn{2}{|c|}{0.0254} & \multicolumn{2}{|c|}{0.0257} \\
\hline
\end{tabular}

Note: Robust standard errors in parentheses; ${ }^{* *} p<0.01,{ }^{* *} p<0.05,{ }^{\star} p<0.1$. 


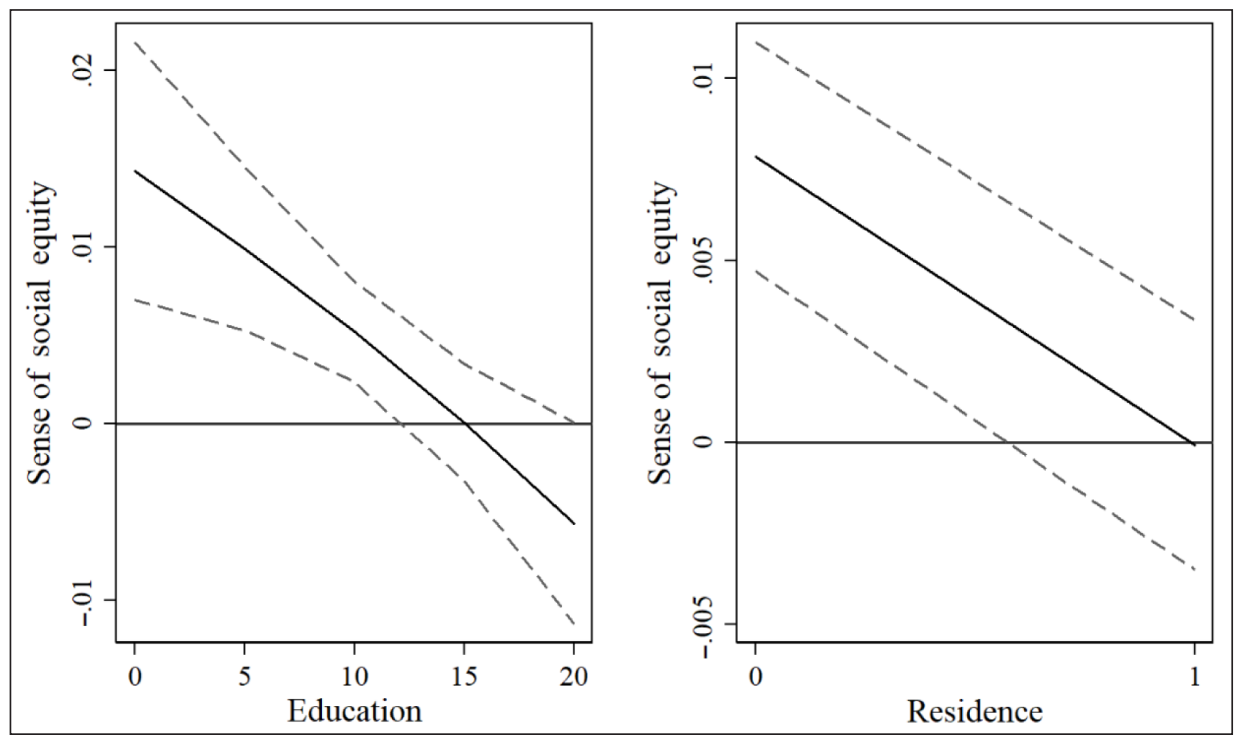

Figure. The number of documents by year, which contain the word "mobility" in the title, abstract or keywords, in the Scopus abstract and citation database from 1850 to 2017

The magnitude of the effects shows that (1) the Internet use has a significant positive marginal effect at the confidential level of $1 \%$ on people's sense of social equity when their educational years are less than or equal to 12 (in China, high school graduates receive 12 years of education), whereas the marginal effect is not significant when people's educational years are greater than 12; (2) for the rural resident, the Internet use has a positive marginal effect on the sense of social equity which is statistically significant with $p=0.000$, whereas the marginal effect is not significant for the urban resident. That is, increasing education and the residence change from rural to urban areas make the negative correlation between the Internet use and people's sense of social equity become moderate gradually.

\section{DISCUSSION AND CONCLUSION}

As one of the most developed countries in the Internet, China deserves in-depth studies on how the Internet affects Chinese society and people. Thus, this paper illuminates the influence of Internet use on people's sense of social equity in China by analysing CGSS2013. The following two findings have emerged from the empirical research of this paper.

(1) In general, the Internet gives people a surprising amount of information, but its use does not make people feel more equitable. The reason for this negative incidence is that the Internet use strengthens people's non-institutionalized political participation (Chen 2013; Harlow 2011; Schumann, Luong 2011). Whereas institutionalized participation is directly related to actions regarding the institutional and electoral process and participants are trying to influence the political system in a direct way, non-institutionalized participation has no such relation and the influence is more indirect. The former forms of political engagement have been in decline in many countries, while the latter forms have started to gain importance. This can be interpreted as a signal that even though citizens are still supporting the democratic 
system, they have become more critical regarding the ways in which democracy is currently functioning (Marien et al. 2010; Stolle, Hooghe 2011). In fact, the non-institutionalized participation is becoming more and more common in China's Internet space, and it includes the network mass incident, network public opinion, network protest, etc. On the one hand, this non-institutionalized participation could help people better understand the true face of their living society which is sometimes covered by the traditional media; on the other hand, people usually focus on the problems that exist in the society, which will reduce people's sense of social equity naturally.

(2) The influence of Internet use on people's sense of social equity varies with their education level and residence. The results of the empirical analysis show that the weakening effect of the Internet use on people's sense of social equity is statistically significant for the less educated and rural people, but insignificant for the higher educated and urban people. The Internet has become the most important source of information, and also the biggest window to look at the living world. Because of the preference for bad news of people and the negative news bias of media, most news people see and hear from the Internet is negative, and repletes with disasters, crime, scandals and corruption. Thus, if people lack the ability to think rationally and parrot every bit of gossip without bothering about basically fact-checking, their views on the society are worse than it actually is. With the increase of education, people's ability to identify rationally and think independently will be improved accordingly. In this case, the higher educated people's sense of social equity will not be affected by their frequency of Internet use, but yes for the less educated people. And the same situation is reflected in the urban and rural differences. Compared with the city people, rural people usually have narrower horizons, which causes them to believe the information from the Internet. As a result, they will underestimate the social fairness. It is conceivable that the factors which affect people's abilities will also affect the relationship between Internet use and their sense of social equity.

Lastly, the development of technologies will not always improve people's sense of social efficiency. In terms of social equity, the more important thing is what measures the government takes to spruce up the lives and well-being of all the citizens.

\section{ACKNOWLEDGEMENTS}

This research is supported by the National Social Science Fund of China (Grant No. 13BSH037), and the Social Science Research Project of the East China University of Political Science and Law (Grant No. 15HZK022).

Received 1 February 2018 Accepted 30 April 2018

\section{References}

1. Alrawabdeh, W. 2014. "Environmental Factors Affecting Mobile Commerce Adoption - An Exploratory Study on the Telecommunication Firms in Jordan", International Journal of Business and Social Science 5(8): 151-164.

2. Barthel, M.; Shearer, E.; Gottfried, J.; Mitchell, A. 2015. The Evolving Role of News on Twitter and Facebook [online]. Available at: http://www.journalism.org/2015/07/14/the-evolving-role-of-news-ontwitter-and-facebook (accessed 31.01.2018).

3. Beckett, C. 2008. SuperMedia: Saving Journalism so It Can Save the World. Oxford: Wiley-Blackwell.

4. Blasio, B. 2015. Ensuring Internet Equality for All [online]. Available at: https://www.huffingtonpost. com/bill-de-blasio/ensuring-internet-equalit_b_6751256.html (accessed 31.01.2018).

5. Brundidge, J. 2006. The Contribution of the Internet to the Heterogeneity of Political Discussion Networks: Does the Medium Matter? Paper presented at the Annual Meeting of the International Communication Association, Dresden International Congress Centre, Dresden, Germany, 16 June 2006. 
6. Castells, M. 2009. The Power of Identity. Malden, MA: Wiley-Blackwell.

7. Castells, M. 2010. The Rise of the Network Society. Malden, MA: Wiley-Blackwell.

8. Chen, Y. 2013. "Does Internet Use Encourage Non-institutional Political Participation? An Instrumental Variable Analysis of the Data from CGSS2006", Society 33(5): 118-143.

9. Christians, C. G. 2016. "Social Justice and Internet Technology", New Media and Society 18(11): 2760-2773.

10. Couldry, N. 2003. Media Rituals: A Critical Approach. London: Psychology Press.

11. Curran, J. P.; Gurevitch, M. 2005. Mass Media and Society. London: Edward Arnold.

12. Gillmor, D. 2004. We the Media: Grassroots Journalism by the People, for the People. Sebastopol, CA: O'Reilly Media.

13. Harlow, S. 2012. "Social Media and Social Movements: Facebook and an Online Guatemalan Justice Movement That Moved Offline", New Media \& Society 14(2): 225-243.

14. Holt, R. 2004. Dialogue on the Internet: Language, Civic Identity, and Computer-Mediated Communication. Westport, CT: Praeger.

15. Li, Q.; Liu, Q.; Chen, Y. 2013. "The Impact of Internet on Social Areas and Some Policy Suggestions", Social Science of Beijing (1): 4-10.

16. Lippmann, W. 1922. Public Opinion. New York: Harcourt, Brace and Co.

17. Marien, S.; Hooghe, M.; Quintelier, E. 2010. "Inequalities in Non-institutionalized Forms of Political Participation: A Multi-level Analysis of 25 Countries", Political Studies 58: 187-213.

18. Rheingold, H. 2002. Smart Mobs: The Next Social Revolution. Cambridge, MA: Perseus Books Group.

19. Riddle, K. 2009. Cultivation Theory Revisited: The Impact of Childhood Television Viewing Levels on Social Reality Beliefs and Construct Accessibility in Adulthood. Paper presented at the Annual Meeting of the International Communication Association, Marriott, Chicago, IL, 21 May 2009.

20. Schneider, F. W.; Gruman, J. A.; Coutts, L. M. 2012. Applied Social Psychology: Understanding and Addressing Social and Practical Problems. Washington, DC: Sage Publications Inc.

21. Schumann, S.; Luong, F. 2011. "Tool for or Source of Action? A Social Psychological Perspective on the Influence of Virtual Worlds on Reality", First Monday 16(6).

22. Shirky, C. 2008. Here Comes Everybody: The Power of Organizing Without Organizations. London: Allen Lane.

23. Stolle, D.; Hooghe, M. 2011. "Shifting Inequalities? Patterns of Exclusion and Inclusion in Emerging Forms of Political Participation”, European Societies 13(1): 119-142.

24. Marc, T.; Stuart, S. 2014. "Consumer Demand for Cynical and Negative News Frames", International Journal of Press and Politics 19(3): 360-379.

25. Xie, Y. H.; Zhao, H. J.; Xie, Q. J.; Arnold, M. 2011. "On the Determinants of Post-entry Strategic Positioning of Foreign Firms in a Host Market: A 'Strategy Tripod' Perspective”, International Business Review 20(4): 477-490.

26. Zuckerman, E. 2014. “New Media, New Civics?” Policy \& Internet 6(2): 151-168.

\section{Interneto poveikis žmonių socialinio teisingumo jausmui}

